\title{
LASTARRIA Y LA REVISIÓN JUDICIAL DE LA LEY EN EL MARCO DE LA CONSTITUCIÓN CHILENA DE 1833
}

\author{
LASTARRIA AND JUDICIAL REVIEW OF LEGISLATION WITHIN THE \\ FRAMEWORK OF THE CHILEAN 1833 CONSTITUTION
}

\section{Sergio Verdugo*}

\begin{abstract}
RESUMEN: Se identifican algunos textos de Lastarria, donde sugirió establecer un sistema de control judicial de la ley en el marco de la Constitución chilena de 1833. Luego de revisar la literatura pertinente, se argumenta que la propuesta de Lastarria fue original entre sus pares académicos conocidos, y la más antigua identificada hasta ahora. Además, el trabajo sostiene que la propuesta de Lastarria es consistente con el resto de su pensamiento político-constitucional relevante.
\end{abstract}

Palabras clave: Control Judicial de la Ley, Lastarria, Liberalismo político.

ABSTRACT: This paper identifies some texts authored by Lastarria, where he suggested to establish a judicial review of legislation system within the framework of the Chilean 1833 Constitution. After reviewing the pertinent literature, the paper argues that Lastarria's proposal was original among his known academic peers, and the oldest currently known. In addition, the claims that Lastarria's proposal was consistent with his relevant politicalconstitutional scholarship.

Key words: Judicial Review of Legislation, Lastarria, Political Liberalism.

\section{INTRODUCCIÓN}

En 1868, J.V. Lastarria propuso la creación de un sistema de control judicial de la ley en Chile, en el contexto de una propuesta constituyente más amplia denominada $L a$ Reforma Política. Única Salvación de La República. Único Medio de Plantear La Semecracia O El Gobierno de Sí Mismo (en adelante, la "Semecracia")1. Dicha idea (en adelante, "la propuesta") fue reiterada por Lastarria en otros textos que revisaré. De esta forma, Lastarria es uno de los precursores del control judicial de la ley en Chile.

Por "sistema de control judicial de la ley", entiendo la facultad de tribunales independientes de revisar la constitucionalidad (y, por tanto, la validez o aplicabilidad) de la legislación. Esta precisión es relevante, ya que en la época de Lastarria se ejercía un tipo

\footnotetext{
Profesor de Derecho Constitucional e investigador del Centro de Justicia Constitucional, Universidad del Desarrollo. Candidato a doctor en Derecho, Universidad de Nueva York (NYU). Máster en Derecho, Universidad de California, Berkeley. Magíster en Derecho Público, P. Universidad Católica de Chile. Dirección postal: 22 Washington Square North, New York, NY 10011, USA. Correo electrónico: sergio.verdugo@law.nyu.edu. Agradezco a José F. García, Fernando Muñoz, Patricio Navia, José M. Díaz de Valdés y Felipe Jiménez por sus comentarios. Agradezco a Francisco Rivadeneira, ayudante de investigación, por su colaboración.

1 Lastarria (1868).
} 
de control constitucional por parte del Congreso y la comisión conservadora ${ }^{2}$. Por ello, la originalidad de la propuesta no radicaba en establecer un sistema de control de constitucionalidad, sino en proponer que sea la Corte Suprema la encargada de ejercer dicha función.

Argumentaré que la propuesta de Lastarria es anterior a otros antecedentes del control judicial de la ley que historiadores y constitucionalistas han identificado en Chile. Varios investigadores han estudiado el pensamiento y vida de Lastarria, pero ninguno parece haber prestado suficiente atención a su pensamiento constitucional. El estudio de esta materia es importante, primero, porque Lastarria fue uno de los intelectuales más importantes del siglo XIX en $\mathrm{Chile}^{3}$; y segundo, porque Lastarria jugó un rol significativo en las reformas políticas que transformaron la Constitución de 1833.

Además de explicar y caracterizar la propuesta de Lastarria, este trabajo tiene otro objetivo: demostrar que dicha idea no era un elemento aislado o accidental del pensamiento de Lastarria, sino que una pieza consistente con la doctrina política liberal que este autor promovió en nuestro país.

Para demostrar mi hipótesis, examinaré los trabajos relevantes de Lastarria en materia constitucional, observando su noción acerca de ideas que, tradicionalmente, han estado vinculadas con las justificaciones del control constitucional de la ley. Me refiero a las nociones de Constitución, derechos fundamentales, soberanía, separación de poderes, y al rol de los jueces. Sumo a ellas la influencia del constitucionalismo norteamericano sobre su pensamiento. Todos estos elementos estuvieron presentes en la obra de Lastarria, y fueron tratados de una manera consistente y compatible con la idea de la revisión judicial de la ley.

Previo a ello, revisaré la literatura constitucional coetánea a Lastarria, para mostrar que su propuesta era original entre sus pares. Además, examinaré las obras constitucionales relevantes posteriores a Lastarria, y las obras especializadas en su pensamiento y vida, para mostrar que la propuesta de este autor, aún no ha sido explorada por la academia.

Hago presente que este trabajo no es producto de una investigación historiográfica (en el sentido de explorar, verificar y teorizar sobre hechos ocurridos en el pasado, o simplemente la producción académica de conocimiento sobre el pasado), sino que de un estudio de las ideas constitucionales de Lastarria ${ }^{4}$. Por ello, este artículo forma parte de la literatura sobre historia de las ideas. Pese a ello, uno de mis argumentos tiene una naturaleza histórica en un sentido limitado: Lastarria presentó la primera propuesta chilena, conocida hasta hoy, respecto del establecimiento de un sistema de control judicial de constitucionalidad de

\footnotetext{
2 Ver una descripción de este sistema de control en Henríquez (2014).

3 Entre los autores abundan los elogios a Lastarria. Cristi y Ruiz-Tagle, p. ej., dicen que "Lastarria es considerado el primer jurista del constitucionalismo chileno”. Cristi y RUIZ-Tagle (2006) p. 99. También, VARAS (2013).

4 En su ensayo sobre la investigación histórica, Robert Hume identifica tres tipos de estudios historiográficos: reconstrucción de documentos del pasado y análisis de hechos, análisis especulativo que ofrece explicaciones ante la limitada evidencia disponible, y teorización histórica donde se identifican patrones generales. HuME (2002) p. 403. Mi trabajo no pertenece a estas categorías. Hume (2002) p. 403.
} 
la ley. Como muchos argumentos que tienen un componente histórico, esta hipótesis podría ser refutada en el futuro si se encuentran propuestas anteriores ${ }^{5}$.

En primera sección (I), revisaré la opinión de los constitucionalistas conocidos del siglo XIX, y constataré que ninguno de ellos realizó una propuesta como la de Lastarria. En segundo lugar (II), verificaré el tratamiento que la doctrina de los siglos XX y XXI le ha dado a la propuesta de Lastarria, demostrando que la misma ha sido, hasta ahora, inexplorada. Enseguida (III), revisaré brevemente la literatura específica sobre Lastarria y daré cuenta que no se ha prestado atención a la propuesta constitucional de este autor. Luego (IV), reproduciré y caracterizaré la propuesta de Lastarria. A continuación (V), revisaré el contexto y las justificaciones de la propuesta de Lastarria, mostrando la manera en que dicha propuesta forma parte de un pensamiento político más amplio. Finalmente (VI), concluyo.

\section{LOS COMENTARISTAS DE LA CARTA DE 1833}

En esta sección, reviso brevemente la opinión de los comentaristas de la Carta de 1833 respecto de la posibilidad de que se instaure un sistema de revisión judicial de la ley. Los autores identificados son Valentín Letelier, Manuel Carrasco, Alcibíades Roldán y Jorge Huneeus. Además, agrego a Andrés Bello y a Manuel Ballesteros. La Tabla 1 resume las posiciones de estos autores, distinguiendo entre quienes eran partidarios de la revisión judicial de la ley, quienes eran contrarios a ella, y quienes sostuvieron visiones incompatibles con ella:

TABLA 1

Posición de los Juristas bajo la Carta de 1833

\begin{tabular}{|c|c|c|c|}
\hline Constitucionalista & A favor & En contra & Ideas incompatibles \\
\hline J. V. Lastarria & $\mathrm{X}$ & & \\
\hline J. Huneeus & & $\mathrm{X}$ & \\
\hline M. Carrasco & & $\mathrm{X}$ & $\mathrm{X}$ \\
\hline V. Letelier & & & \\
\hline A. Roldán & & $\mathrm{X}$ & $\mathrm{X}$ \\
\hline M. Ballesteros & & $\mathrm{X}$ & \\
\hline A. Bello & & & \\
\hline
\end{tabular}

Huneeus, al comentar la Carta de 1833, explicaba que los jueces no deben desobedecer la ley, ni siquiera si ella es inconstitucional ${ }^{6}$. Fundaba esta conclusión en tres argumentos: (1) si el Presidente no debía desobedecer la ley, menos lo debían hacer los jueces?. (2) La Constitución no le entrega el poder de controlar la ley a los jueces, sino solo al Congreso. Luego, las Cortes no pueden juzgar los actos del Congreso, sino solo aplicar las

\footnotetext{
5 Una investigación puede llevar a "una buena respuesta provisional", siendo importante reconocerla como tal para valorar su verdadero peso. Hume (2002) p. 419.

6 Huneeus (1880) p. 252.

7 Huneeus (1880) pp. 252-253.
} 
leyes que éste $\mathrm{crea}^{8}$. (3) El control constitucional de la ley solo puede justificarse en sistemas federalistas (como el norteamericano), y como Chile es un Estado unitario, no existen razones para justificar su instauración en nuestro país ${ }^{9}$. Los argumentos 1 y 2 se sustentan en la Carta de 1833, por lo que más que genuinos argumentos normativos, se trata de interpretaciones que justifican las reglas vigentes en esa época. No obstante, el argumento 3 sí parece ser una razón genuinamente normativa, en el sentido de que es independiente de las reglas constitucionales, siendo un juicio sobre la (in)conveniencia de adoptar un modelo de control constitucional.

Esta misma línea argumentativa fue seguida por autores de otras disciplinas, como ocurrió con el influyente político y juez, Manuel Ballesteros ${ }^{10}$. Poco después, Alcibíades Roldán, revisando las fuentes del Derecho Constitucional, identificaría el poder de la Corte Suprema norteamericana de dejar sin efectos las leyes del Congreso, comentando que esta práctica es importante en "aquellos otros países de régimen federal"11.

Otra razón que se invocó para rechazar la instauración del sistema de revisión judicial de la ley, es la concepción de la soberanía como poder ilimitado. Dicha visión de la soberanía fue asociada al concepto de ley adoptado por Andrés Bello en el Código Civil ${ }^{12}$. En palabras de Roldán: "Desde que la ley es una declaración de la voluntad soberana manifestada en el modo que la Constitución determina, no es admisible que un poder diferente del legislativo posea una atribución semejante"13.

Varios de estos autores eran críticos de la Carta de 1833. La diferencia entre ellos y Lastarria no obedece a su oposición o defensa de dicha Constitución, sino a la manera en que ellos se aproximaron al poder de los tribunales de justicia. Entre ellos, Lastarria fue el único que propuso establecer el sistema de revisión judicial de la ley, aunque no fue el único en criticar la manera en que el poder judicial estaba organizado en esa época. Así, por ejemplo, Carrasco cuestionaba el estatuto de los jueces y la forma en que ellos carecían de independencia real ${ }^{14}$, pero al mismo tiempo los consideraba como aplicadores de la ley a hechos particulares ${ }^{15}$ y estimaba que era “(...) más lojico conceder la atribución de interpretar la Constitucion al Poder Lejislativo que al Judicial” debido, en parte, a la "(...) vaguedad de la lei suprema"16.

\footnotetext{
8 Huneeus (1880) p. 253.

9 Huneeus (1880) p. 254.

10 Ballesteros relata que en la historia de la ley orgánica de tribunales se contenía una disposición que establecía: "El poder judicial no tiene la facultad para dictar disposiciones jenerales, ni para impedir o suspender por motivo alguno la ejecución de una lei”. Dicha norma no habría sido aprobada por innecesaria, ya que habría estado implícita en el texto. BAllesteros (1890) p. 21. Así, esta ley reafirmaría el rechazo al control judicial de la ley existente antes de la Carta de 1925.

11 RoldÁn (1917) p. 25.

12 Bello creía que los jueces debían aplicar la ley, no importando si ella fuera injusta. BELLo (1836) pp. 265266.

13 RoldÁn (1917) p. 467.

14 Ver también el problema de las remuneraciones de los jueces en CARrasco (1874) p. 150.

15 Carrasco (1874) p. 148.

16 Carrasco (1874) p. 198.
} 
Algo similar podemos observar en la obra de Letelier. Pese a que prestó poca atención a las facultades de los jueces y no dijo nada sobre la revisión judicial de la ley, Letelier tenía un concepto reducido de jurisdicción que era incompatible con la revisión judicial. La jurisdicción, para Letelier, era (i) una forma de solucionar conflictos entre particulares y (ii) un mecanismo para perseguir a los responsables por hechos punibles, prefiriendo que los jueces se atengan al tenor literal de la ley ${ }^{17}$.

En suma, la doctrina de la época, salvo por Lastarria, rechazaba explícitamente la idea de la revisión judicial de la ley (Huneeus, Carrasco, Roldán, Ballesteros), o tenía ideas incompatibles con ella (Letelier, Bello).

\section{LOS CONSTITUCIONALISTAS Y EL CONTROL DE CONSTITUCIONALIDAD}

En esta sección reviso brevemente la manera en que doctrina constitucional bajo la constituciones de 1925 y de 1980 trata el problema del control judicial de la ley en la época de Lastarria. Mostraré que la doctrina no identifica la propuesta de Lastarria, existiendo un consenso en torno a que bajo la Carta de 1833 solo existía un control político de constitucionalidad, con la excepción de ciertos casos anecdóticos que se suelen citar, en general tomados de Huneeus.

Además de esos casos (a los que referiré), se ha constatado que bajo la Carta de 1833 existió una temprana especie de jurisprudencia de equidad (que contrasta con la tradición legalista $)^{18}$, citándose casos donde los jueces aplican leyes de manera ultraactiva o prescinden del uso de la ley de manera explícita ${ }^{19}$. No obstante, de las fuentes citadas por los autores no puede colegirse la existencia consciente de una facultad para revisar judicialmente la ley.

Bajo la Carta de 1925, interesa examinar la obra de José G. Guerra (1929), Rafael Raveau (1939), Carlos Estévez (1949), Mario Bernaschina (1951), Alejandro Silva (1963), Mario Quinzio (1969), Raúl Bertelsen (1969), Enrique Evans (1970, 1973) y Carlos Andrade (1971). En la Tabla 2, resumo sus opiniones respecto del comienzo del control judicial de la ley en Chile. En ella, identifico si el autor cree que el control constitucional comenzó con la Carta de 1925, si el autor cita los casos excepcionales usados por Huneeus como antecedente previo, y si agrega un antecedente que, siendo previo a la Carta de 1925, no responde a los casos usados por Huneeus, ni a las discusiones constituyentes de la propia Constitución de 1925.

17 Letelier (1917) p. 650.

18 En especial Brahm (1990).

19 Ver otros ejemplos en NúNÉz (2012) p. 213. 
Tabla 2

Comentaristas de la Carta de 1925

\begin{tabular}{|c|c|c|c|}
\hline Autor & $\begin{array}{c}\text { Comienza en la } \\
\text { Carta de 1925 }\end{array}$ & Cita casos de Huneeus & Agrega antecedente \\
\hline J. G. Guerra & $\mathrm{X}$ & & $\mathrm{X}$ \\
\hline R. Raveau & $\mathrm{X}$ & & $\mathrm{X}$ \\
\hline C. Estévez & $\mathrm{X}$ & $\mathrm{X}$ & $\mathrm{X}$ \\
\hline M. Bernaschina & $\mathrm{X}$ & $\mathrm{X}$ & $\mathrm{X}$ \\
\hline A. Silva & & $\mathrm{X}$ & \\
\hline M. Quinzio & $\mathrm{X}$ & & \\
\hline R. Bertelsen & & $\mathrm{X}$ & $\mathrm{X}$ \\
\hline E. Evans & $\mathrm{X}$ & $\mathrm{X}$ & \\
\hline C. Andrade & $\mathrm{X}$ & & \\
\hline
\end{tabular}

La gran mayoría de los comentaristas de la Carta de 1925 reconoce que el control constitucional comienza con dicha Constitución. Guerra sostiene que la inaplicabilidad establecida en 1925 es algo "completamente nuevo en nuestro país" ${ }^{20}$, y luego entrega ejemplos de leyes que sobrevivieron pese a su inconstitucionalidad ${ }^{21}$. Raveau observa que un control político habría comenzado con la Carta de $1818^{22}$, pero que solo sería incorporado como atribución propiamente judicial con la Carta de $1925^{23}$. Una precisión similar sería realizada por Estévez ${ }^{24}$, Quinzio ${ }^{25}$, y (aunque con matices) por Bertelsen ${ }^{26}$. Bajo la Carta de 1833, los jueces carecían de la facultad de dejar una ley sin aplicación por ser inconstitucional ${ }^{27}$, y algunos casos demuestran lo anterior ${ }^{28}$. Para Estévez, estos casos muestran que, antes de la Carta de 1925, el problema se presentó de forma "rudimentaria"29. Fue la Carta de 1925, como dice Estévez, Bernaschina y Andrade, la que consagró por primera vez el control constitucional de la ley ${ }^{30}$. Además, Andrade citaría algunas opiniones jurisprudenciales posteriores que reconocerían lo mismo ${ }^{31}$. Más breves son Quinzio y Evans, aunque

20 GUERRA (1929) p. 457.

21 GUERRA (1929) p. 458.

22 Raveau (1939) p. 382.

23 Raveau (1939) p. 383.

24 Estévez (1949) p. 347.

25 Andrade, citando a Alessandri y a Somarriva, dice que la opinión unánime de la doctrina y jurisprudencia era "que el juez no podía dejar de aplicar una ley inconstitucional". ANDRADE (1971) p. 633.

26 Bertelsen (1969) p. 135.

27 Raveau (1939) p. 383.

28 Estévez cita algunos casos. Estévez (1949) pp. 346-347.

29 Raveau (1939) p. 383.

30 Estévez dice que el control fue introducido por la Carta de 1925, variando "la práctica de casi un siglo de vida constitucional". Estévez (1949) p. 347. Bernaschina destaca a la inaplicabilidad dentro de las "innovaciones", siendo la "facultad más importante" de la Corte Suprema. Bernaschina (1951) pp. 45-46. Esta facultad "se venía pidiendo desde muchos años atrás". Bernaschina (1951) p. 542.

31 Andrade (1971) p. 633. 
ellos también reconocen lo anterior ${ }^{32}$. A ello, Evans agrega (con ocasión de la instauración del primer Tribunal Constitucional el año 1970) que hasta antes de la creación del Tribunal Constitucional, no existía en Chile "un órgano de la naturaleza" de ese tribunal ${ }^{33}$, al que consideraba "absolutamente nuevo, sin precedentes en nuestra historia política" ${ }^{34}$.

Un caso aparte es el de Alejandro Silva. Si bien este autor señala que el recurso de inaplicabilidad es una de las "diferencias sustanciales" de la Carta de 1925 en relación a la de $1833^{35}$, luego realiza una precisión que lo diferencia del resto: Silva parece partidario de una interpretación por la cual la Carta de 1833 repudiaba la ley inconstitucional, primero, por el concepto de ley, y segundo, por la existencia de algunos casos (tomados de otros autores) donde, durante la segunda mitad del siglo XIX, se habrían ignorado preceptos legales por no ser constitucionales ${ }^{36}$.

Para Silva, entonces, la Carta de 1833 no establecía explícitamente el control judicial de la ley, pero era posible ejercerlo de igual forma. El primero de los casos citados por Silva trata acerca de una circular de la Corte Suprema, y el segundo de una sentencia. Una lectura atenta de estos casos, no obstante, sugiere que ellos estaban lejos de justificar la facultad de revisar judicialmente las leyes como tal. En el primer caso la Corte Suprema concluye que la supremacía del legislador impide invalidar la legislación inconstitucional, cuestión que debe ser corregida por el propio Congreso ${ }^{37}$, y en el segundo ocurre una situación excepcional que obedece más bien a un problema de inexistencia ${ }^{38}$. Este segundo caso también podría ser interpretado (como lo hace Bertelsen) como un ejemplo en que la Corte declara la inconstitucionalidad de forma ${ }^{39}$. No obstante, ya sea "inexistencia" o "inconstitucionalidad de forma", de este caso no debe inferirse que la Corte haya desarrollado una doctrina que justifique explícitamente la facultad de los tribunales para revisar la ley. A

32 Quinzio argumenta a favor del control sobre el legislador asociando la inaplicabilidad con la supremacía constitucional. También agrega que fue la Carta de 1925 la que entregó este poder a la Corte Suprema. Quinzio (1969) pp. 496-510. Evans dice que fue la Carta de 1925 la que "consagró la institución de la Inaplicabilidad". Evans (1973) p. 17.

33 Evans (1973) p. 64.

34 EVANs (1973) p. 63.

35 Ver Silva (1963) p. 59 y p. 62.

36 Silva (1963-A) p. 432.

37 Me refiero a la decisión de 2 de enero de 1867, cuando la Corte Suprema le envió a la Corte de Apelaciones una opinión relativa al problema del control judicial de la ley. Silva interpreta esa opinión como favorable al poder de controlar la constitucionalidad de la ley. No obstante, antes de llegar a la parte citada por Silva, como lo documenta Navarro, la Corte Suprema sostuvo que las leyes promulgadas gozan de la autoridad suprema del legislador en relación al problema de su compatibilidad con la Constitución. En definitiva, la Corte no ordenó invalidar la regulación inconstitucional, señalando que el problema debía corregirse mediante el propio Congreso y a través de la derogación del decreto que estaba en juego. NAVArRo (2011) p. 17. Lamentablemente, la cita de Silva, ha influido a otros académicos que lo han seguido. BERTELSEN (1969) p. 136, Ríos (2002) p. 44

38 La misma Corte desconoce la existencia de disposiciones legislativas que no fueron aprobadas por el Senado (sino solo por la Cámara). Se trata de la decisión de 1 de marzo de 1876. La Corte constataría una violación al proceso legislativo cometido por la Cámara de Diputados, por lo que las normas aprobadas "no tienen el carácter de una ley". Silva (1963-A) p. 432.

39 BeRTELSEN (1969) p. 136. Es importante considerar que este autor también reconoce que ningún órgano estaba "facultado expresamente para declarar la inconstitucionalidad de una ley". BerTELSEN (1969) p. 137. 
lo más, de este caso puede inferirse el desarrollo de una visión limitada donde se protege la facultad legislativa del Congreso (o del Senado, según se mire).

En suma, la mayoría de los comentaristas de la Carta de 1925 reconoce que bajo la Carta de 1833 no existía control judicial de la ley, y una minoría introduce matices que, en todo caso, no constituyen la existencia de un sistema de control.

Los comentaristas de la Constitución de 1980 no se diferencian de esta conclusión. Las fuentes utilizadas se reiteran y son pocos los antecedentes nuevos que se aportan, salvo tal vez por Navarro, quien identifica una propuesta formulada por el ex Presidente Balmaceda ${ }^{40}$. En 1891, Balmaceda habría propuesto sin éxito la creación de un árbitro institucional llamado a resolver las disputas entre el Congreso y el Presidente, que en esa época se agudizaban ${ }^{41}$. Dicha propuesta, formulada en el contexto de la guerra civil que experimentaba nuestro país, habría fracasado. Si bien la idea de Balmaceda merece ser estudiada con mayor profundidad, la misma es posterior a la propuesta de Lastarria.

El resto de los autores contemporáneos ofrecen perspectivas similares a las anteriores. Así, p. ej., Núñez cita una sentencia de 1895 donde se rechaza explícitamente la facultad de revisar judicialmente la ley, como ejemplo de la doctrina predominante de esa época ${ }^{42}$, mientras Zúñiga y Nogueira caracterizan el sistema de control constitucional bajo la Constitución de 1833 como un "control político" ${ }^{43}$, idea desarrollada con mayor profundidad por Henríquez ${ }^{44}$. Por su parte, Aldunate y Zapata comienzan sus narrativas sobre el control constitucional mencionando la inaplicabilidad de la Carta de $1925^{45}$, la que sería reconocida por otros autores como "una innovación mayor" 46 . Asimismo, autores como Ribera, Zúniga, Friedler, Hilbink, Núñez y Delaveau, reconocerían un consenso académico en torno a la idea de que bajo la Constitución de 1833 no había control constitucional, salvo por el rol del propio Congreso ${ }^{47}$. Esta misma idea es compartida por un amplio número de autores, como Figueroa, Peña, Navia y Muñoz ${ }^{48}$.

Una excepción es la opinión de Lautaro Ríos, para quien la Carta de 1833 consagraba preceptos que podrían haber permitido el ejercicio del control judicial de la ley ${ }^{49}$. Con todo, Ríos ofrece una interpretación particular del texto del siglo XIX que no es comparti-

\footnotetext{
40 Navarro (2010) p. 1236; Navarro (2011) pp. 30-31.

41 Se trataba de un tribunal externo al Poder Judicial, compuesto por 9 miembros nombrados por los tres poderes del Estado (cada poder nombra 3). Entre otras cuestiones, el tribunal resolvería la constitucionalidad de las leyes. Sagredo y Devés (1991) p. 369. Llama la atención la similitud de este diseño con el propuesto por Hans Kelsen años después. Ver el discurso completo (20 de abril de 1891) en SAGredo y Devés (1991) pp. 359-370.

42 NúNẼEZ (2012) p. 214.

43 Zúñiga (2002-A) p. 444; Nogueira (1993) p. 436; ZúNiga (2002) pp. 16-17.

44 Henríquez (2014).

45 Zapata (2002) p. 10; Aldunate (2009) p. 5. Zapata dice que este recurso es un "tímido primer paso" en la historia del control de constitucionalidad. ZapaTA (2002) p. 10.

46 Couso et al. (2013) p. 30.

47 Ribera (1987) p. 81; ZúNiga (2002) p. 14; Friedler (2000) p. 327; Hilbink (2007) p. 47; NúÑez (2012) p. 213; Delaveau (2014) p. 469.

48 Figueroa (2013) pp. 382-393; Peña (2011) p. 18; Muñoz (2005) p. 267; Navia (1999) p. 10.

49 Ríos (2002) p. 45.
} 
da por los tratadistas y tribunales de la época. La interpretación de Ríos obedece más a una aproximación normativa del propio autor que a una descripción fiel de la Carta de 1833 o de su aplicación.

Hoy, es común para los investigadores consideren que el Poder Judicial bajo la Carta de 1833 no fuera realmente un poder independiente del Estado, sino tan solo una suerte de apéndice ${ }^{50}$. Así, la independencia judicial era una meta ideal futura y no un principio institucional asegurado ${ }^{51}$. Se considera que los jueces en esa época eran "esclavos de la ley" que debían aplicarla literalmente ${ }^{52}$, que carecían de mecanismos judiciales en contra del Gobierno $^{53}$ y que la Carta de 1833 desconocía "el carácter de Poder Público al [Poder] Judicial"54. Existía "el dogma de la soberanía de la ley", lo que era congruente con un diseño que favorecía al Presidente de la República en desmedro de los tribunales ${ }^{55}$. A ello se sumaba una desconfianza hacia el rol de los jueces, lo que se combinaba con un formalismo propio de la tradición jurídica Europeo-continental, formalismo que comenzaba a ser importado a Chile ${ }^{56}$. Todos estos elementos, entienden los autores, habrían contribuido a crear una cultura judicial débil, propensa a rechazar la idea del control judicial de la ley ${ }^{57}$.

Ninguno de los autores consultados en esta sección ha identificado la propuesta de Lastarria como un antecedente relevante del control judicial de la ley. Ello no significa que dichos autores no estén familiarizados con la obra de Lastarria (algunos lo citan explícitamente ${ }^{58}$ ), sino que quienes utilizan el trabajo de Lastarria parecen interesarse en contribuciones diferentes de su obra, como su interpretación de la Carta de 1833. Probablemente quien más se acerca al pensamiento de Lastarria en materia de facultades de los tribunales es Zúñiga. Este autor identifica las críticas de Lastarria en contra del "poder conservador"59, la defensa de la existencia de tribunales ordinarios (y no especiales) y de un concepto amplio del poder jurisdiccional ${ }^{60}$. No obstante, Zúñiga no examina ni da a conocer la propuesta de Lastarria de establecer un control judicial de la ley.

Del estudio de los trabajos citados más arriba, puede inferirse que los autores (salvo por Silva y Bertelsen, quienes introducen matices) coinciden en que el control judicial de la ley comenzó con la Carta de 1925. Los antecedentes previos a esa Constitución (como los casos que suelen citarse o la mención a Balmaceda) parecen ser excepcionales y no

50 Cristi y Ruiz-Tagle (2006) p. 98.

51 BRAVO (1976) p. 80.

52 Hilbink (2007) p. 48.

53 Bravo (1976) p. 78. Esta habría sido la concepción de Mariano Egaña. Bravo (2003) p. 541.

54 Guerra (1929) p. 430.

55 ZÚNiga (2002) p. 18.

56 Hilbink (2007) pp. 48-51. Esto habría sido especialmente aplicable durante el régimen portaliano: en la "primera mitad del siglo diecinueve, entonces, un legalismo evolucionó en Chile, combinando los principios legales positivistas de Andrés Bello con la intervención autoritaria y limitaciones inspiradas en Diego Portales” (original en inglés, la traducción es mía). Hilbink (2007) p. 51. También, Friedler (2000) p. 326.

57 Otros dicen que las Cortes eran políticamente irrelevantes. Couso et al. (2013) p. 25.

58 Se suelen citar comentarios aislados de Lastarria sobre la Carta de 1833, pero no identifican su propuesta en torno a crear el control judicial de la ley, p. ej. Navarro (2011) p. 16.

59 ZúNiga (2002) pp. 21-22.

60 ZÚNiga (2002) p. 27. 
representativos de la realidad de la época, bajo la cual existía una noción débil del poder de los jueces.

\section{LA LITERATURA SOBRE LASTARRIA}

En esta sección, reviso brevemente la literatura específica sobre Lastarria, constatando que ninguno de los autores examinados se ha detenido con profundidad en sus propuestas constitucionales. Como consecuencia de ello, esta literatura no ha identificado la propuesta de Lastarria relativa al control judicial de la ley.

Entre los trabajos críticos del pensamiento de Lastarria, destacan las obras de Cruz y de Oyarzún. El primero defiende el pensamiento católico-conservador (al que Lastarria atacó con su liberalismo) y no profundiza realmente en las ideas de Lastarria, sino que se limita a atacar su personalidad y a cuestionar su trabajo académico, acusándolo de carecer de originalidad y de no proponer soluciones sensatas ${ }^{61}$. Oyarzún, por su parte, profundiza en el pensamiento de Lastarria cuestionando su verdadero carácter de filósofo y su trabajo como historiador $^{62}$. Dedica varias páginas a explorar su recepción del positivismo, su pensamiento liberal, su relación con la literatura, la educación e incluso sus ideas económicas, entre otros. No obstante, poco dice de las propuestas constitucionales de Lastarria.

Probablemente los dos trabajos más importantes sobre Lastarria son el de Fuenzalida y el de Subercaseaux. El primero escribió un libro esencialmente biográfico donde solo se constatan algunas generalidades sobre la Semecracia ${ }^{63}$, los Elementos de Derecho Público $^{64}$ y las Lecciones de Política Positiva ${ }^{65}$. Por su parte, Subercaseaux profundiza en el pensamiento de Lastarria de una manera analítica y descriptiva ${ }^{66}$. Este libro se interesa por las novelas, los cuentos y la historiografía de Lastarria, y también por su liberalismo y positivismo. Sin embargo, Subercaseaux no se detiene en las propuestas específicas de cambio constitucional.

Junto con los trabajos recién citados, se encuentran algunos artículos que han explorado el pensamiento de Lastarria. Sacks, por ejemplo, examina la relación entre Lastarria y Sarmiento ${ }^{67}$, la influencia de Buckle en Lastarria ${ }^{68}$, y una pequeña biografía político-intelectual de Lastarria ${ }^{69}$. Trabajos de otros autores se han enfocado en la relación de Lastarria

\footnotetext{
61 Cruz (1917).

62 Oyarzún (1953). Existieron otros cuestionamientos al carácter académico de Lastarria. Abdón Cifuentes, en sus Memorias (1936), dice que los estudios de Lastarria "no tuvieron base sólida y ordenada", aunque reconoce que sus trabajos son superiores a los de su época, pese a "la escasez de elementos de que dispuso y al atraso de las ciencias políticas entre nosotros". Cifuentes narra un episodio en que Lastarria habría sido sorprendido cometiendo "crasos errores de catecismo, de historia y de jurisprudencia". Cifuentes (1936) pp. $209-211$.

63 Fuenzalida (1893) p. 286.

64 Fuenzalida (1893) pp. 100-101.

65 Fuenzalida (1893) p. 340.

66 Subercaseaux (1981).

67 SACKS (1988).

68 SACKS (1988-A).

69 SACKS (1972).
} 
con el positivismo ${ }^{70}$, y en aspectos de su vida desde una perspectiva biografía, como su relación con Andrés Bello y la Universidad de Chile ${ }^{71}$, además de su contribución a la enseñanza jurídica ${ }^{72}$. Existen también algunas obras que han explorado a Lastarria desde una perspectiva más amplia ${ }^{73}$, pero su generalidad no les ha permitido profundizar en sus propuestas concretas.

A este grupo de trabajos podemos sumar otros donde el pensamiento de Lastarria es analizado de forma más general ${ }^{74}$. No obstante, ninguno de estos trabajos ha registrado la propuesta de Lastarria sobre el control judicial de la ley.

Sin perjuicio de lo anterior, las obras citadas en esta sección son útiles para entender el contexto intelectual en que la propuesta concreta de Lastarria fue formulada.

\section{LA PROPUESTA DE LASTARRIA}

En esta sección, reproduzco y caracterizo la propuesta de Lastarria en torno a la creación de un control judicial de la ley.

La idea fue presentada en un folleto denominado Semecracia ${ }^{75}$. El folleto habría sido una reacción frente a un programa ministerial que no satisfizo la agenda de reformas que Lastarria promovía ${ }^{76}$. Lastarria habría publicado la Semecracia para desarrollar un plan político inspirado en el modelo constitucional norteamericano ${ }^{77}$, y destinado a corregir un sistema represivo cuyo eje era la figura de un ejecutivo supremo ${ }^{78}$.

Es importante tener presente que el folleto de la Semecracia fue una versión más sofisticada de un documento anterior denominado Bases de La Reforma (1850), publicado en coautoría con el diputado Errázuriz ${ }^{79}$. Bases... contenía un programa político liberal con decenas de propuestas concretas, entre ellas, el fortalecimiento del Poder Judicial, al que denomina como "supremo poder judiciario" 80 . En este documento, se proponía establecer una Corte Suprema con jueces electos popularmente, sujetos a una sola reelección, y con poderes sobre todo el Poder Judicial, entre otras. No obstante, este documento no se pronunciaba respecto de la posibilidad de que los jueces controlaran la constitucionalidad de la ley, lo que sí aparece en la Semecracia.

\footnotetext{
70 Woll (1976) pp. 493-506. También, SiLVA (2008).

71 Fuchslocher (1988) pp. 51-90. Lastarria presta atención a su debate con Bello relativo al método histórico y, también, por el debate literario. Ver su Recuerdos Literarios (1878).

72 Barrientos (1988) pp. 91-122.

73 P. ej. De Ávila Martel (1988) pp. 13-26.

74 Donoso (1946); Jocelyn-Holt (1998); Hale (1996) pp.133-206; JaKsic (1989); Silva (2008).

75 La expresión "semecracia” es una simplificación gramatical de la traducción que el propio Lastarria hacía de la expresión inglesa "self-government": "el gobierno de si mismo" o "el gobierno del pueblo por el pueblo". LASTARria (1868) p. 10. También, Oyarzún (1953) pp. 97-98.

76 Fuenzalida (1893) pp. 283-286.

77 Oyarzún (1953) p. 54.

78 Fuenzalida (1893) pp. 286.

79 Fuenzalida (1893).

80 Lastarria y Errázuriz (1850) pp. 20-21.
} 
En esta última, Lastarria ofreció un diagnóstico crítico del sistema político que regía en la época, y propuso establecer un "gobierno semecrático, del pueblo por el pueblo, un gobierno del cual no puedan apoderarse las ambiciones personales o de círculo"81: "Ensáyese con lealtad al self-government de los norte-americanos, la semecracia o gobierno del pueblo por el pueblo, i veremos si necesitamos tener más ilustración que la que poseemos, para ejercer nuestros derechos políticos, i para dejar de ser víctimas de las ambiciones innobles, de las oligarquías personales i de los intereses mezquinos de círculo" 82 .

Dentro de las reformas específicas que se ofrecen dentro de su modelo de Semecracia, Lastarria propuso crear una nueva Corte Suprema: "El supremo poder judicial debe establecerse en una Corte Suprema compuesta de nueve magistrados i un procurador nacional elejidos cada diez años, i reelegibles, por electores en número igual al de diputados, elejidos directamente por la nación"83. "Respecto de la jurisdicción, la Corte Suprema ejerce, en primer lugar, la jurisdicción política, la cual tiene por único i principal objeto defender la Constitución contra las leyes arbitrarias que la violen o contra las que no sean conforme a ella, debiendo la Corte ejercer esta jurisdicción solo en los casos en que se recurra a ella para que declare, en un litigio privado, si tal o cual lei es o no constitucional, aplicada al caso sobre que versa la contención entre un ciudadano i cualquiera parte que pretenda aplicar dicha lei $[\ldots]^{\prime \prime 4}$.

De esta forma, Lastarria cree que el control constitucional es un tipo de jurisdicción política. Lastarria no lo dice de forma explícita, pero es fácil inferir que se refiere a un tipo de control en su versión ex post ("a posteriori” o "represivo", porque opera una vez que la ley sujeta al control haya entrado en vigencia), ya que se requiere de "un caso" y un "litigio privado". Además, parece tratarse de un control con efectos limitados a la controversia jurídica en cuestión (“aplicada al caso...”).

Lastarria ofreció un articulado preciso para la reforma que proponía. En su Bosquejo de una Constitución Política Arreglada a los Principios i Doctrina de la Ciencia ${ }^{85}$, Lastarria propuso un texto positivo para reemplazar la Carta de $1833^{86}$. En dicho texto, se sugirió establecer una Corte Suprema de 12 miembros elegidos cada 10 años, en un proceso que incorpora la elección dentro de las Asambleas Provinciales, siguiendo la regla de mayoría de 2/3, y la participación posterior del Congreso (art. 61) ${ }^{87}$. La Corte Suprema nombra a los jueces subalternos (art. 62) ${ }^{88}$. Luego, dentro de las atribuciones de la Corte Suprema, se considera resolver "todos los juicios políticos que la Constitución le señala, en única instancia” (art. 68, No 1) y, dentro del recurso de casación, la Corte Suprema conoce de dicho recurso "entablado contra las resoluciones o sentencias de todas las autoridades i de los tribunales nacionales o provinciales, por ser contrarias a la Constitución, por falsa aplicación

\footnotetext{
81 LASTARRIA (1868) p. 6.

82 LASTARRia (1868) p. 10.

83 LASTARRia (1868) p. 12.

84 LASTARRia (1868) p. 13.

85 Este Bosquejo se incluye como apéndice en Lastarria (1874).

86 Ver una defensa del sistema federal en Lastarria (1874) pp. 295-303.

87 LASTARRIA (1874) p. 541.

88 LASTARRIA (1874) p. 542.
} 
de una lei inconstitucional o constitucional, i por haber faltado a los procedimientos que garantizan la defensa del derecho" ${ }^{\text {89 }}$.

Además de estas reglas, Lastarria también propuso otras normas relevantes: Art. 9: "Los actos lejislativos de las Asambleas provinciales que sean contrarios a su Constitución o a la Constitución i leyes de la República están sujetos a suspensión i anulación conforme a lo dispuesto en esta Constitución" ${ }^{\circ}$. Art. 12, No 8: "El derecho de objetar ante el tribunal competente todo fallo judicial fundado en una lei contraria a la Constitución, i toda resolución espedida en un caso particular la cual puede ser acusada de inconstitucional o de ilegal" $"$.

Como puede observarse, Lastarria considera que (i) la legislación de las asambleas son susceptibles de declararse inconstitucionales (art. 9), y que (ii) la facultad de pedir la declaración de inconstitucionalidad es un derecho político (junto con el de sufragio y el de petición). Este derecho era (iii) el único que no podía ser suspendido ni siquiera en caso de "conmoción interior o de guerra estranjera" (art. 14) ${ }^{92}$, y (iv) siendo superior a la ley, la que no podía alterarlo: "Los principios o garantías que se declaran en el art. 11 no pueden ser alterados por las leyes civiles, i los derechos políticos enumerados en el artículo anterior no pueden serlo por las leyes que reglamenten su ejercicio, ni la enumeración de aquellas garantías i de estos derechos implica una negativa de otros retenidos por el pueblo o reconocidos en otras disposiciones de esta Constitución o por las leyes arregladas a ella" ${ }^{\prime 3}$.

Una característica adicional relevante de la propuesta de Lastarria dice relación con las facultades del Congreso, el que también debía tener la facultad para "Decidir por una lei las dudas o cuestiones que ocurran a las autoridades sobre la intelijencia de la Constitución i acerca de la vijencia o de la constitucionalidad de las leyes" (art. 39, No 17) ${ }^{94}$.

De esta manera, Lastarria se habría inclinado por permitir que todos los poderes del Estado interpreten la Constitución, situando, para estos efectos, a todos los poderes del Estado en una jerarquía equivalente. Aunque no es claro que Lastarria conociera las doctrinas departamentalistas norteamericanas (y que rechazara la denominada judicial supremacy), su propuesta se asemeja bastante a ellas. Con todo, hay tener presente que Lastarria también era escéptico del rol que el Congreso debía cumplir para interpretar la Constitución. Su escepticismo obedecía a la existencia de intereses políticos al interior del Congreso que pu-

89 LASTARria (1874) pp. 543-544.

90 Lastarria (1874) p. 512.

91 LASTARria (1874) p. 519.

92 Lastarria (1874) p. 520.

93 LASTARria (1874) pp. 519-520.

94 Lastarria (1874) p. 530. En otro texto, comentando la facultad del Congreso para "interpretar, explicar y detallar, por medio de leyes especiales, las disposiciones de la Constitución”, Lastarria diría: "El uso de esta atribución puede ser un importante y provechoso efecto para la República, puesto que por medio de leyes pueden ser, si no modificados, a lo menos aplicados en un buen sentido los preceptos del Código Fundamental, y neutralizados, hasta cierto punto, los males que pueden nacer de sus defectos o de la falsa aplicación de sus disposiciones." Texto reproducido por Navarro (2010), quien lo toma de Derecho Público Constitucional Teórico o Filosófico (1906) p. 473. 
dieran primar por sobre los principios de justicia ${ }^{95}$. Dichos intereses hacían posible la dictación de leyes inconstitucionales ${ }^{96}$.

La defensa de un sistema de revisión judicial de la ley también fue hecha por Lastarria en su Lecciones de Política Positiva. En dicha obra, Lastarria muestra admiración por el sistema de EE.UU., país que tenía un sistema de revisión judicial de la ley por el cual "cualquiera sea la disposición lejislativa que las restrinja o ataque [refiriéndose a las libertades], es de suyo inconstitucional i nula, i los tribunales no la aplican, llegando el caso de un juicio, considerándola como no existente" 97 . Para Lastarria, esto muestra la manera en que debe limitarse el poder político, cuestión que no ocurrió en algunas partes de Europa. Por ello, Lastarria es crítico de la declaración de derechos del hombre en Francia, la que considera "simplemente una esposición doctrinaria (...) que no fue una limitación del poder político, quien ya entonces ejercía la dictadura del terror, no solo para castigar a los traidores, sino aun para perseguir a los indiferentes" 98 .

Luego, agrega: "La América ha dado en esto un paso jigantesco: ha creado un poder judicial independiente, ha colocado entre las leyes del congreso i la Constitución al poder judicial. Este no tiene atribución de declarar que una lei es mala, ni de hacer observaciones; pero en un litijio privado si se halla colocado entre dos leyes, la suprema del país, adoptada por el pueblo como fundamento del edificio político, a la cual está sometido el lejislativo, i la lei del congreso, las compara i declara la supremacía de la primera"99.

En suma, Lastarria creía en el establecimiento de un control judicial de la ley, lo que asociaba a la estructura federal que proponía, inspirándose para ello en el modelo norteamericano. No obstante, las reglas que proponía no eran idénticas a las del sistema norteamericano, ya que Lastarria intentaba corregir el problema democrático de la justicia constitucional reconociendo que se trataba de una jurisdicción propiamente política, que debía ser ejercida mediante un Poder Judicial subordinado a una Corte Suprema que tuviera algún grado de legitimidad democrática, y que no tuviera la exclusividad en la interpretación de la Constitución ${ }^{100}$.

\footnotetext{
95 "Con todo, es una verdadera desgracia que los intereses políticos sean en la mayor parte de los casos los que dicten una resolución complementaria o esplicativa de la Constitución, i no los principios de justicia o el bien del país. Este es un mal irremediable, entre tanto, i solo el patriotismo y la integridad pueden evitarlo." LASTARRIA (1865) p. 484.

96 Así, cuando se refiere a las leyes que el legislador dicta para complementar la Constitución, Lastarria es consciente que ellas pueden ser objeto de "una lucha abierta entre la lei fundamental i las leyes secundarias". LASTARRIA (1865) pp. 484-485.

97 LASTARria (1874) pp. 271-272.

98 Lastarria (1874) p. 272.

99 Lastarria (1874) pp. 458-459.

100 La propuesta de que la Corte Suprema fuera electa parece un rasgo común a varias obras de Lastarria. Ella está presente no solo en Bases de La Reforma, Semecracia, Bosquejo y Lecciones..., sino también en su comentario a la Carta de 1833, donde plantea que la Corte "debe ser elejida en el mismo período que el Presidente de la República i por los mismos electores de este (...)”. Lastarria (1865) p. 348.
} 


\section{JUSTIFICACIÓN DE LA PROPUESTA DE LASTARRIA}

La propuesta de Lastarria se sitúa dentro de un pensamiento más amplio. Como mostraré en esta sección, su consistente con su liberalismo político y su versión limitada del positivismo.

Nadie pone en duda el compromiso liberal de Lastarria ${ }^{101}$, ni su oposición al régimen conservador portaliano ${ }^{102}$. Es sabido también que Lastarria estuvo influido por el positivismo de Augusto Comte, especialmente en Lecciones de Política Positiva. Lastarria construyó un sistema de pensamiento para explicar cómo debe ser la organización social, convenciéndose, por ejemplo, que el sistema federal "es el único réjimen de gobierno armónico con las enseñanzas científicas”"103.

Este tipo de afirmaciones positivistas pueden cuestionar el real compromiso liberal de Lastarria, ya que Comte no era precisamente un liberal, y su filosofía incluso poseía algunos rasgos autoritarios. Una posible explicación radica en la falta de ilustración de Lastarria en estas materias. Así, p. ej., se ha dicho que Lastarria "apenas si reparó" en las contradicciones del positivismo y del liberalismo ${ }^{104}$. Una segunda explicación reconoce que Lastarria fue selectivo en su utilización del positivismo, resolviendo la tensión en favor del liberalismo ${ }^{105}$. Si se considera que Lastarria rechazó explícitamente las ideas antiliberales de Comte ${ }^{106}$ y su antiindividualismo ${ }^{107}$, y se limitó a utilizar el pensamiento comteano casi exclusivamente para sustentar el estudio científico de la política ${ }^{108}$, esta segunda explicación parece más plausible. Si ello es así, entonces puede reducirse la importancia de la tesis de Patricio Silva, quien sostiene que el positivismo de Lastarria fue uno de los fundamentos históricos de nuestra inclinación tecnocrática ${ }^{109}$. El vínculo entre las ideas positivistas de Lastarria con los tecnócratas del siglo XX es bastante débil (si existe), y su utilización del positivismo no tuvo por objeto justificar políticas públicas concretas, sino establecer las bases del sistema político en términos más generales. Si hay algo que pudiera unir a Lastarria con los tecnócratas es su confianza en la ciencia. No obstante, eso no vuelve a Lastarria un tecnócrata.

\footnotetext{
101 Ver Campos (1963) p. 163; Edwards (1972) p. 72; SaCKS (1972) p. 193; Subercaseaux (1981) p. 35; De Ávila Martel (1988) p. 20; Collier y Sater (2004) p. 106.

102 Lastarria es considerado el más importante enemigo intelectual la Carta de 1833. Donoso (1946) p. 448; Gargarella (2013) p. 69.

103 Fuenzalida (1983) p. 315.

104 Oyarzún (1953) p. 54. Oyarzún consideraba a la formación filosófica de Lastarria como "desordenada y pobre”. OYARZÚN (1953) p. 51.

105 JaKSIC (1989) pp. 36-37. Esto último es aceptado por SiLVA (2008) p. 31. Lastarria puso sus conocimientos filosóficos al servicio de una agenda de reformas políticas. Silva (2008) p. 23-39. Lo mismo ocurría con su visión de la historiografía, donde valoraba más la interpretación política que la mera descripción de datos, lo que le valió un famoso debate con Bello. SACKS (1972) pp. 167-168. En especial, Oyarzún (1953) pp. 69-80.

106 Ver Woll (1976).

107 HaLe (1996) pp.154-15.

108 Lastarria también se interesó por el positivismo por sus críticas contra la Iglesia. JAKSIC (1989) p. 43.

109 SiLVA (2008).
} 
En lo que sigue, revisaré la forma en que Lastarria trata algunos elementos relevantes para la organización del Poder Judicial en general y del control judicial de la ley en particular. En todos ellos es posible identificar manifestaciones de su liberalismo político.

\section{A) El rol de la CONSTitución y los Derechos Fundamentales}

Para Lastarria, las constituciones tenían por objeto limitar el poder y proteger los derechos. Por ello, era crítico tanto de las constituciones que carecían de límites al poder como de las leyes que afectaban los derechos.

Las primeras eran consideradas como "inútiles y a veces nugatorias" cuando, entre otras razones, reconocen derechos "tratando de garantizarlos sin sanción efectiva, sin limitar la soberanía nacional ni el poder político, i dejándolos al arbitrio de los mandatarios, al de las leyes que se dicten posteriormente [...]"110. Por su parte, las leyes que afectaban derechos eran denominadas como "leyes anulativas de los derechos individuales", y se producen cuando la Constitución da espacio para la regulación y limitación de los derechos ${ }^{111}$.

La Constitución debiera limitarse a "formular aquellos derechos i prohibir al poder lejislativo el dictar sobre ellos ni leyes ni decisiones"112, además de establecer con precisión los límites del poder ${ }^{113}$. Siguiendo a Joseph Story, agrega Lastarria: "en una Constitución limitada que a la vez prescribe las atribuciones de los gobernantes i los derechos de los ciudadanos [...] el poder judicial mantendrá el equilibrio [...] poniendo un freno práctico a los actos del gobierno i dando un vigor positivo a los derechos de los ciudadanos"114.

Como ya lo constaté, la revisión judicial de la ley era considerada como un derecho político que no podía suprimirse por el legislador ${ }^{115}$. La propuesta es consistente con una visión constitucional que maximiza los derechos fundamentales en contra de un Estado limitado. De lo anterior no se sigue necesariamente la necesidad de adoptar el control judicial de la ley (existen otros mecanismos para limitar el poder y proteger derechos), pero se abre espacio para justificarlo y, al menos, para fortalecer la necesidad de que las "leyes anulativas de derechos" sean eliminadas efectivamente.

\section{B) La SObERANía, LA SEPARACión DE FUnCIONES Y EL ESTADO DE DERECHO}

En su Bases de La Reforma, Lastarria presenta una lista de "principios fundamentales”, donde se contiene una visión limitada de la soberanía y una visión concreta de la división de poderes, ambas lejanas de los conceptos tradicionales que imperaban en esa época $^{116}$. Estas concepciones serían explicadas con mayor detalle en Lecciones de Política

\footnotetext{
110 LASTARria (1874) p. 273.

111 LASTARria (1874) pp. 280-281.

112 LASTARria (1874) p. 405.

113 Lastarria (1896) p. 50.

114 LASTARria (1896) pp. 463-464.

115 Considera que el principio de responsabilidad del mandatario exige la existencia de una "acción popular para perseguirlo por perjuicios o por infracción de su mandato ante la justicia ordinaria”. LASTARRIA (1874) p. 418.

116 Lastarria y ERrázuriz (1850) pp. 9-10.
} 
Positiva, donde considera a la soberanía absoluta un "absurdo"117, y la soberanía ilimitada "absurdo capital"118. Lastarria creía que la soberanía absoluta era "hipócrita" por servir el interés de concentrar el poder ${ }^{119}$.

La limitación de la soberanía para Lastarria tenía dos enemigos: el pensamiento absolutista y la tradición democrática rousseauniana. Respecto del segundo enemigo, se ha dicho que Lastarria se aleja de Rousseau negando que el hombre entregue una parte de sus derechos al Estado a través de un contrato social120. Además, "como liberal, Lastarria no toleraría el abrumar al individuo por las masas ni toleraría el sujetar al individuo al dominio del estado absoluto"121. Así, Lastarria rechaza la tiranía de la mayoría, considerándola igual de peligrosa que al Estado absoluto ${ }^{122}$.

En otro texto, Lastarria intentó reconciliar el carácter absoluto del poder político con los límites que este ofrecía. Esto, que podría parecer una contradicción, es explicado: "la soberanía nacional tiene su fundamento en el principio de justicia y solo en él puede hallar sanción de todos sus actos, porque si la sociedad se desvía de este principio, o los que ejercen a su nombre la soberanía, obra contra su propio fin y consiguientemente contra todos los preceptos de la razón, que es el fundamento y único origen de la justicia. Y no se crea que al establecer que la soberanía nacional es limitada sentamos un principio contradictorio, que destruye el poder social en su base, porque precisamente este poder no existe en la sociedad sino para la consecución de su fin racional, y nada sería más contrario a este fin que un poder amplio y absoluto, en virtud del cual fuese posible apartarse de los dictados de la razón y de la justicia" ${ }^{123}$.

Esta idea de soberanía limitada lleva a Lastarria a rechazar explícitamente la "soberanía del pueblo", entendiendo por aquella "la supremacía de la voluntad jeneral"124. Así, la soberanía no debía ser entendida como el "predominio de la voluntad de las masas, del populacho, que precisamente es en la América española el que carece de voluntad propia, i que, por el lamentable atraso en que se encuentra, puede servir mejor a las miras siniestras de los demagogos"125. "De esta forma queda condenada la falsa doctrina de la democracia absoluta, cuya forma jamás ha existido"126, a la que considera "imposible"127.

Esta idea de la soberanía marcó una diferencia entre Lastarria y los intelectuales de la época, entre quienes (como ya vimos) imperaba una concepción ilimitada de ella ${ }^{128}$.

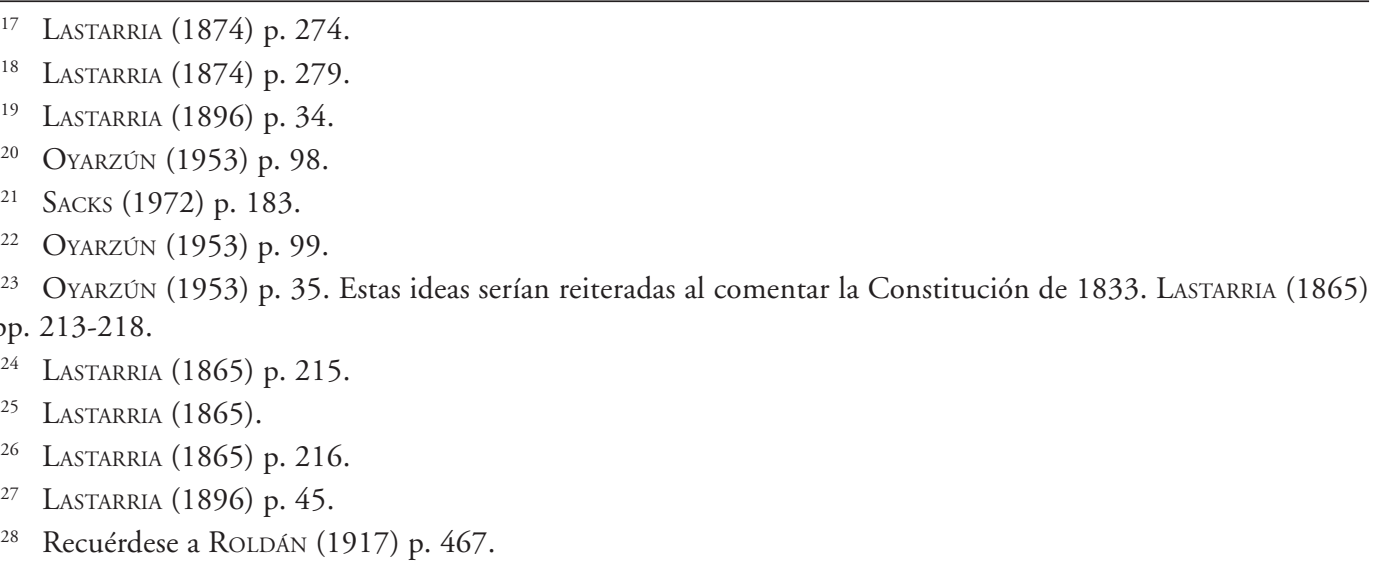


Aplicado al Poder Legislativo, la concepción de Lastarria sobre la soberanía tenía como consecuencia el establecer límites a dicho poder, ya que de lo contrario el mismo no sería muy distinto del poder que ejerce una monarquía absoluta ${ }^{129}$. Por ello, la idea de soberanía limitada se ha asociado a la separación de funciones estatales, frente a la cual Lastarria dice seguir tradiciones filosóficas como las de "Blackstone i Montesquieu"130. Así, Lastarria argumenta que la unión de los "departamentos" legislativo, ejecutivo y judicial, "son causa de despotismo o de anarquía"131, y que la "concentración del poder" es "el mal por excelencia” 132 . Las "ramas del poder político" debían estar separadas, ya que las "usurpaciones que mutuamente pueden hacerse y la confusión de sus diversas esferas de acción, son causas de despotismo y ponen a la libertad trabas temibles [...]"133. No obstante, los poderes no deben separarse de manera tan radical, porque "cuando los poderes están tan separados que no haya lazo social ninguno entre ellos, hay anarquía"134.

Lastarria desarrolla también una idea cercana al Estado de Derecho. Aunque no usó ese término, las ideas de Lastarria conducen fácilmente hacia esa dirección. En palabras de Oyarzún: "Al Estado todopoderoso sustituye el de derecho, cuya misión consiste en representar el principio jurídico en la sociedad [...]"135. En palabras del propio Lastarria, utilizando un principio político norteamericano: la "máxima fundamental de la república-que ella es el gobierno de las leyes i no el de los hombres"136.

El mismo Lastarria lo deja claro en otro texto: "El poder legislativo no puede ser en ningún caso ilimitado, sino que debe ceñirse siempre al principio del derecho para promover los intereses generales [...]. De aquí se sigue que el legislador no ha de tener un poder discrecional sino cuando el punto en cuestión sea problemático o controvertible [...]. Pero cuando no hay más que una sola opinión y el principio de justicia aparece tan claro, que no dé lugar a controversias, el poder del legislador no puede ser discrecional, porque no podría ordenar lo que fuese contrario a ese principio. Según esa doctrina es evidente que el poder legislativo no debe en ningún caso traspasar los límites de lo justo ni imponer sacrificios innecesarios, cualquiera que sea el pretexto de que se valga, porque de otro modo sería tiránico y faltaría al espíritu de su institución, haciéndose acreedor al castigo que debe imponerse a los que abusan de la autoridad"137.

Estas ideas fácilmente sirven para entender al Poder Judicial como un órgano equivalente a los otras en jerarquía, y también para justificar la idea de frenos y contrapesos. La literatura de la época también se refería a una suerte de poder inspectivo, que consistía en velar porque los "poderes constituidos [...] cumplan sus deberes y no traspasen o se inva-

\footnotetext{
129 Fuenzalida (1893) p. 100.

130 Lastarria (1874) p. 287.

131 LASTARria (1874) p. 288.

132 Oyarzún (1953) p. 96.

133 Lastarria (1896) p. 43.

134 LASTARria (1896).

135 Oyarzún (1953) p. 95.

136 Lastarria (1874) p. 463.

137 LASTARria (1896) p. 54.
} 
dan recíprocamente sus atribuciones"138. Bajo la Carta de 1833, este poder estaba entregado parcialmente a la comisión conservadora. Lastarria era contrario a establecer una institución independiente que vigilara al resto de los poderes del Estado y, en cambio, promovía el fortalecimiento del Poder Judicial y, en especial, la reducción del enorme poder de que gozaba el Presidente de la República. Para Lastarria, una institución especial distinta "fácilmente podría abusar de sus facultades o por lo menos embarazar la acción general del poder" ${ }^{\prime 39}$. Si bien Lastarria no conocía al modelo de Tribunal Constitucional Kelseniano (que sería propuesto muchos años después), lo anterior nos permite especular: Lastarria probablemente lo hubiera rechazado. En cambio, Lastarria prefería que a cada rama del poder se le entregaran "ciertas atribuciones destinadas a rechazar los avances que pudieran hacer a su respectiva autoridad los agentes de algunos poderes políticos y a mantener la armonía y equilibrio de sus facultades y obligaciones recíprocas" ${ }^{140}$.

En suma, el pensamiento de Lastarria era incompatible con la idea imperante en la época, bajo la cual la soberanía y la separación de poderes debían producir que los jueces se limitaran a pronunciar las palabras de la ley ${ }^{141}$. El tipo de soberanía y de separación de poderes defendidos por Lastarria daban espacio a que los jueces jugaran un rol mayor.

\section{C) El MODELO NORTEAMERICANO}

Las ideas recién expuestas estuvieron influidas por la admiración que Lastarria tenía por el constitucionalismo anglosajón en general ${ }^{142}$, y el norteamericano en particular ${ }^{143}$. Aunque es probable que varias de las observaciones de Lastarria puedan ser imprecisas ${ }^{144}$, no puede argumentarse que esta admiración se fundara en un conocimiento pobre del sistema norteamericano.

A modo de ejemplo, puede verse (i) su extenso comentario a una obra de Joseph Story (un influyente comentarista de la Carta norteamericana ${ }^{145}$ ), la probable influencia de "Gladstone" (sic) ${ }^{146}$ y las citas al ex Presidente Adams ${ }^{147}$; (ii) su consideración al derecho "de cargar i tener armas" (art. 12, No 4 del Bosquejo); (iii) su preferencia por el sistema de jurados (que no recomienda importar inmediatamente) ${ }^{148}$; y (iv) su preferencia por el esta-

138 LASTARRIA (1896) p. 127.

139 LASTARria (1896).

140 LASTARria (1896) p. 129.

141 Esta versión de la separación de poderes era ampliamente compartida, como habría ocurrido con Mariano Egaña. Bravo (2003) p. 541.

142 Hale (1996) p. 155.

143 SACKS (1972) p. 190.

144 Por ejemplo, Lastarria creía que el common law exigía un sistema de control judicial de la ley: "Estas garantías son las máximas del common law que constituye la herencia del pueblo inglés, i por eso es que, si por una suposición imposible, el parlamento quisiere atacar aquellas garantías por medio de una lei no cabe duda de que los jueces la declararían en oposición con el common law i por lo tanto inaplicable". LASTARRIA (1874) p. 458.

145 Lastarria (1874) pp. 461-464.

146 Donoso (1946) p. 290.

147 Jocelyn-Holt (1988) p. 456.

148 Lastarria (1896) pp. 97-101. 
blecimiento de tribunales ordinarios y no especiales (rechazando explícitamente el modelo francés ${ }^{149}$. También, varios autores han notado la influencia del pensamiento de Bentham en Lastarria, aunque la influencia de Bentham no fue tan importante en su pensamiento específicamente constitucional, sino en otras obras como Principios de Legislación Universal $^{150}$ y Teoría del Derecho Penal ${ }^{151}$.

En otro texto, denominado La América, Lastarria estudió las diferencias entre Europa y el nuevo mundo ${ }^{152}$. En la América, Lastarria luchó contra el legado español y la idea de que habría una raza latina en América, a la que consideraba una idea napoleónica absolutista ${ }^{153}$. Lastarria consideraba a Europa como heredera de una tradición monárquica donde se concentra el poder. En cambio, América se organizaba en torno a la idea de libertad y republicanismo. Para ello, Lastarria se sirve de héroes como Washington y Bolívar ${ }^{154}$. De esta manera, por ejemplo, Lastarria dedica un capítulo a explicar lo que denomina "Ignorancia de la Europa en materias de gobierno republicano"155 y a defender la doctrina Monroe ${ }^{156}$, entre otros temas que abarca.

La admiración de Lastarria por EE.UU. es importante para efectos de este trabajo, ya que en esa época EE.UU. era el único país conocido que poseía un sistema de revisión judicial de la ley. Es altamente probable que la idea la haya extraído de allí, tanto en la Semecracia, como en los textos posteriores.

\section{D) LAs CRÍticas a la CARTA de 1833}

Gran parte del liberalismo de Lastarria se elaboró contra la tradición conservadora y las ideas portalianas que inspiraron a la Carta de 1833, la que representaba el triunfo de los conservadores contra los liberales en Lircay. Los textos de Lastarria dan cuenta del ataque liberal al régimen conservador-portaliano, especialmente su Bases de La Reforma, Semecracia y sus Elementos de Derecho Público Constitucional Teórico, Positivo I Político Y La Constitución Política de La República de Chile Comentada. Lo propio ocurrió con un

\footnotetext{
149 "Si la organización del departamento judicial en una Constitución libre, federal o unitaria, debe ser calculada para reprimir las usurpaciones i garantizar los derechos de los ciudadanos, es lójico que no se admitan en ella jurisdicciones especiales o excepcionales, que no hacen más que mantener privilejios i armar al Estado de un poder incompatible con [...] los derechos de la sociedad. Por consiguiente [...] no cabe lo que según la moda francesa se llama jurisdicción administrativa, porque no hai razonamiento serio alguno para que los procesos en que es parte la administración contra los contribuyentes, contra sus contadores, o compradores, o arrendatarios, proveedores o empresarios, sean juzgados por ella misma o sus agentes". LASTARRIA (1874) pp. $472-473$.

150 Barrientos (1988) pp. 103-106.

151 FuenZalida (1893) p. 96. En todo caso, Lastarria abandonó rápidamente su admiración por Bentham. En un informe dirigido al decano de Derecho de la U. de Chile, Lastarria sugirió "desterrar" de los programas las obras de Bentham, "aunque tenga que arrojar al fuego los Elementos de Legislación Universal”. Lastarria agrega que Bentham tiene una "filosofía sensualista" que "lo aniquila todo; desprecia la historia y aún desconoce el Derecho Romano". Ver el informe en Barrientos (1988) pp. 117-121.

152 LASTARria (1865).

153 Hale (1996) pp. 135-136. Original en inglés. La traducción es mía.

154 También, ver Subercaseaux (1981) pp. 220-222.

155 LASTARria (1865) pp. 27-34.

156 LASTARria (1865) pp. 139-162.
} 
ensayo titulado Don Diego Portales, Juicio Histórico, donde Lastarria critica fuertemente las ideas y la personalidad de Portales.

En algunos de estos documentos, Lastarria muestra la forma en que el régimen hacía ilusoria la independencia judicial. Así, por ejemplo, en su Don Diego Portales..., Lastarria critica la Carta de 1833 por afectar la independencia judicial ${ }^{157}$, rechaza la concentración del poder en manos de Portales ${ }^{158}$, y lo acusa de crear una "dictadura" ${ }^{159}$ que mantiene el orden a costa de la violencia política ${ }^{160}$.

Otro ejemplo está en el folleto de la Semecracia. En dicho texto, Lastarria acusa directamente la falta de independencia del Poder Judicial: "Lo que hai en el fondo de esta lucha es una invasión atentatoria que el gobierno emprende contra la independencia del poder judicial, bajo el pretesto de atacar i de arruinar a aquel partido en sus últimos atrincheramientos”161 “¿Qué esperanzas ofrece al país una situación semejante? ¿En dónde hallará la salvación de sus derechos? ¿A dónde buscará las garantías del orden público i de la tranquilidad que necesita para vivir i trabajar? Si el gobierno provoca i atiza los odios, si emplea su autoridad en servicio de planes personales, si invade el poder judicial para arrojar a sus adversarios i apoderarse de esos puestos, a fin de dominar en toda la línea"162.

Por otra parte, Lastarria no era amigo de la Comisión Conservadora establecida bajo la Carta de 1833. Dicha comisión, que era especialmente relevante durante el receso del Congreso, estaba compuesta por un grupo de senadores que, entre otras funciones, velaba sobre la "observancia de la Constitución i de las leyes"163. Esta función era la "más vaga i la que menos aplicación puede tener" ${ }^{64}$. Lastarria se muestra pesimista del rol de control de constitucionalidad que esta comisión puede ejercer, resultando ser un artículo "ilusorio i de ningún efecto en la organización del Estado, i así lo prueba también la circunstancia de no haber sido jamás practicado, a pesar de que no han faltado ocasiones a su aplicación” ${ }^{165}$.

\section{E) El ROL DE LOS JUeCES}

Como ya lo adelanté previamente, en la época de Lastarria los jueces eran considerados como servidores del legislador ${ }^{166}$. La visión dominante era la de Andrés Bello, para quien la ley era una "declaración de la voluntad soberana..." (art. 1, Código Civil) que solo podía ser interpretada o explicada de "modo generalmente obligatorio" por el legislador y no por el juez (art. 3, Código Civil). Los jueces, por su parte, debían preferir las expresiones literales de la ley (art. 19, Código Civil) y aplicarlas pese a la existencia de obje-

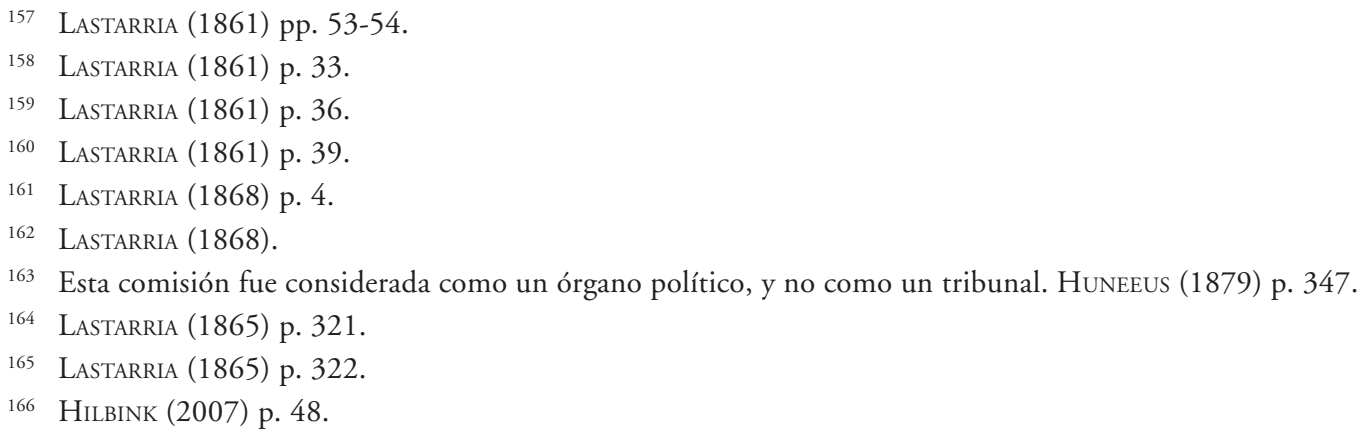


ciones de justicia ${ }^{167}$. Así, se hacía prevalecer al legislador por sobre los tribunales ${ }^{168}$. De esta manera, el Poder Judicial era una especie de apéndice de los poderes políticos ${ }^{169}$. En estas condiciones, la idea de un control judicial de la ley era lejana.

Por su parte, Lastarria no creía que los jueces debían subordinarse al legislador. Por el contrario, Lastarria era escéptico del legislador y no habría, probablemente. Lastarria valora el rol que el Poder Judicial debe tener en lo que denomina "Gobierno libre" (cuyo antónimo, para Lastarria, es la monarquía). En dicho Gobierno, el Poder Judicial debe proteger los derechos de las minorías en contra de las mayorías: "la persecución política viene a ser la causa de la comunidad contra uno, i es más violenta e inflexible porque se considera indispensable para mantener el poder y gozar de la victoria" ${ }^{170}$. Por ello, y siguiendo a Story, Lastarria cree que la independencia judicial debe ser protegida con la permanencia de los jueces ${ }^{171}$, evitando de esta forma que los jueces obedezcan la voluntad de quien los puede nombrar, ascender y remover ${ }^{172}$.

Las ideas anteriores, unidas a la conveniencia de establecer un sistema federal, llevaron a Lastarria a defender el control judicial de la ley. No obstante, para Lastarria la existencia de un Estado unitario no era obstáculo para establecer una jurisdicción de este tipo: "no hai inconveniente alguno para hacer lo mismo en los [regímenes] consolidados o unitarios, donde tal vez es más conveniente i necesario que el supremo tribunal tenga la jurisdicción política para mantener la Constitución, poniendo una valla a los otros poderes i vigorizando los derechos de los ciudadanos" 173 .

Por otra parte, Lastarria quería fortalecer la legitimidad del Poder Judicial, promoviendo la elección popular de los jueces de la Corte Suprema, ya que esta, entre otras facultades, ejerce "la representación del carácter político [...]. Así puede i debe ser elejido popularmente para dar a este departamento una verdadera delegación nacional” ${ }^{174}$. Esta Corte Suprema, además, debía contar con garantías institucionales que aseguraban su independencia ${ }^{175}$, y debía ella nombrar al resto de los jueces" ${ }^{176}$.

El sistema que proponía era, desde luego, contrario al de la Carta de 1833, la que concentraba el poder en el Presidente de la República, "dando al poder judicial un orijen que de ningún modo es democrático, i que es idéntico al que, por una verdadera transac-

\footnotetext{
167 Ver BeLLo (1836) pp. 265-266. También, ver un análisis de las reglas de interpretación de la ley a propósito de la interpretación literalista en ZAPATA (2008) pp. 170-176.

168 La doctrina constitucional actual parece no compartir la filosofía política del Código Civil, ya que ella ignoraría algunos pilares del constitucionalismo moderno. También, la jurisprudencia constitucional ha sido reticente a aplicar las reglas del Código Civil para interpretar la Constitución. Zapata (2008) pp. 170-172. También, ver VARAS (1984).

169 Cristi y Ruiz-Tagle (2006) p. 98.

170 Lastarria (1874) p. 462.

171 LASTARria (1874) p. 463.

172 LASTARria (1874).

173 LASTARria (1874) p. 466.

174 Lastarria (1874) p. 467.

175 LASTARria (1874).

176 LASTARRIa (1874).
} 
ción entre el principio democrático i el monárquico, tiene ese poder en las monarquías constitucionales" 177 .

Como puede observarse, la propuesta de Lastarria en torno a la creación de un sistema de control judicial de la ley parece consistente con su pensamiento más general, el que se organiza bajo el liberalismo político, un uso selectivo del positivismo y la influencia norteamericana.

\section{CONCLUSIONES}

Lastarria propuso el establecimiento del control judicial de la ley bajo el marco de la Constitución chilena de 1833. El autor se inclinaba por entregarle dicha atribución a la Corte Suprema, institución que, para el propio Lastarria, debía ser objeto de reformas tendientes a incrementar su legitimidad. Dicha propuesta formó parte de la agenda de reformas con las cuales Lastarria promovió la transformación del régimen constitucional Portaliano, en un sistema inspirado en la doctrina liberal.

Esta propuesta es la más antigua conocida en Chile hasta ahora.

La propuesta en estudio no era una idea aislada del pensamiento constitucional de Lastarria, sino que formaba parte de la doctrina liberal (de especial influencia angloamericana) que dicho autor promovía. En efecto, la revisión judicial de la ley era consistente con la concepción de Lastarria acerca de la Constitución (cuyo fin es limitar el poder y proteger los derechos fundamentales), el rechazo a la idea de soberanía absoluta y la valoración de los jueces como actores relevantes dentro de la estructura constitucional. Todas estas ideas fueron, hasta la época de Lastarria, minoritarias en nuestro país.

\section{BIBLIOGRAFÍA CITADA}

Aldunate L., Eduardo (2009): Jurisprudencia Constitucional 2006-2008. Estudio Selectivo. (Santiago, Editorial LegalPublishing).

Andrade G., Carlos (1971): Elementos de Derecho Constitucional Chileno (Santiago, Editorial Jurídica de Chile, segunda edición).

Ballesteros, Manuel (1890): La Lei de Organización I Atribuciones de Los Tribunales de Chile (Santiago, Imprenta Nacional).

Barrientos G., Javier (1988): "Lastarria Y El Derecho", en Estudios Sobre José Victorino Lastarria (Santiago, Ed. de la Universidad de Chile) pp. 91-122.

Bello, Andrés (1836): “Observance of the Laws", en (1997) Selected Writings of Andrés Bello (EE.UU., Oxford University Press) pp. 261-269.

Bernaschina G., Mario (1951) Manual de Derecho Constitucional. Tomo II (Santiago, Editorial Jurídica de Chile, vol. 38).

Bertelsen R., Raúl (1969): Control Constitucional de La Ley (Santiago, Editorial Jurídica de Chile). 
Brahm G., Enrique (1990): “¿Jurisprudencia Creativa? La Corte Suprema de Justicia 1841 1860", Revista Chilena de Historia del Derecho, vol. 16: pp. 555-566.

Bravo L., Bernardino (1976): "Judicatura E Institucionalidad En Chile (1776-1876). Del Absolutismo Ilustrado al Liberalismo Parlamentario" Revista de Estudios Histórico-Jurídicos, P. Universidad Católica de Valparaíso, vol. 1: pp. 61-87.

Bravo L., Bernardino (2003): "La Corte Suprema de Chile 1823-2003. Cuatro Caras en 180 Años", Revista Chilena de Derecho, P. Universidad Católica de Chile, vol. XXX, No 3: pp. 535-547.

Campos H., Fernando (1963): Historia Constitucional de Chile (Santiago, Editorial Jurídica de Chile, 3a ed.).

Carrasco A., Manuel (1874): Comentarios Sobre La Constitución Política de 1833. (Santiago, Imprenta de la Librería del Mercurio, 2da ed.).

Cifuentes, Abdón (1936): Memorias, Tomo I (Santiago, Nascimento) .

Collier, Simon y Sater, William (2004): A History of Chile, 1808-2002 (Cambridge, Cambridge University Press, 2da ed.).

Couso, Javier, Lovera, Domingo, Guiloff, Matías y Coddou, Alberto (2013): Constitutional Law in Chile (Kluwer Law International) .

Cristi, Renato y Ruiz-Tagle, Pablo (2006): La República en Chile. Teoría y Práctica del Constitucionalismo Republicano (Santiago, LOM Ed.).

Cruz, Pedro (1917): Estudios Críticos Sobre D. J. Victorino Lastarria (Santiago, Librería y Casa Editorial de la Federación de Obras Católicas).

De Ávila Martel, Alamiro (1988): “Semblanza de José Victorino Lastarria”, en Estudios Sobre José Victorino Lastarria (Santiago, Ed. de la Universidad de Chile) pp. 13-26.

Délano, Luis E. (1944): Lastarria. El Pensamiento de América (México, Ed. de la Secretaría de Educación Pública).

Delaveau, Rodrigo (2014): "El Control de Constitucionalidad. Fundamentos, Historia y Debate Actual Sobre el Rol del Tribunal Constitucional”, en García G., José (ed.), ¿Nueva Constitución O Reforma? Nuestra Propuesta: Evolución Constitucional (Santiago, Editorial LegalPublishing): pp. 461-490.

Donoso, Ricardo (1946): Las Ideas Políticas en Chile (México: Fondo de Cultura Económica, Colección Tierra firme).

Edwards V., Alberto (1972): La Fronda Aristocrática (Santiago, Editorial del Pacífico, 7a Ed.).

Estévez G., Carlos (1949): Elementos de Derecho Constitucional Chileno (Santiago, Editorial Jurídica de Chile).

Evans de la Cuadra, Enrique (1973): Chile, Hacia Una Constitución Contemporánea. Tres Reformas Constitucionales (Santiago, Editorial Jurídica de Chile).

Evans de la Cuadra, Enrique (1970): Relación de la Constitución Politica de la República de Chile (Santiago, Editorial Jurídica de Chile).

Faundez, Julio (2007): Democratization, Development, and Legality. Chile 1831-1973 (EE. UU., Palgrave Macmillan).

FigueroA, Dante (2013): "Constitutional Review in Chile Revisited: A Revolution in the Making”, Duquesne Law Review, vol. 51: pp. 387-419. 
Friedler, Edith (2000): "Judicial Review in Chile", Southwestern Journal of Law \& Trade in the Americas, vol. 7: pp. 321-347.

Fuchslocher A., Luz M. (1988): "Lastarria En La Universidad de Chile”, en Estudios Sobre José Victorino Lastarria (Santiago, Ed. de la Universidad de Chile) pp. 51-90.

Fuenzalida G., Alejandro (1893): Lastarria I Su Tiempo. Su Vida, Obras E Influencia En El Desarrollo Político E Intelectual de Chile (Santiago, Imprenta Cervantes).

Gargarella, Roberto (2013): Latin American Constitutionalism 1810-2010. The Engine Room of the Constitution (EE.UU., Oxford University Press).

Guerra, José G. (1929): La Constitución de 1925 (Santiago, Anales de la Universidad de Chile-Establecimientos Gráficos Barcells \& Co.).

Hale, Charles (1996): "Political Ideas and Ideologies in Latin America, 1870-1930." en Bethell, Leslie (ed.), Ideas and Ideologies in Twentieth Century Latin America, (Cambridge, Cambridge University Press) pp. 133-206.

Henríquez V., Miriam (2014): "El Modelo de Control Político de Constitucionalidad de las Leyes Imperante en Francia y Chile Durante los Siglos XVIII Y XIX”, en Nuñez, José (ed.), Teoría Constitucional. Ensayos Escogidos (Santiago, Ed. Universidad FinisTerrae).

Hilbink, Lisa (2007): Judges beyond Politics in Democracy and Dictatorship: Lessons from Chile (EE.UU., Cambridge University Press).

Hume, Robert (2002): "The Aims and Limits of Historical Scholarship", The Review of English Studies, vol: pp. 399-422.

Huneeus, Jorge (1879): La Constitución Ante el Congreso, o Sea Comentario Positivo de la Constitución Chilena. Primera Parte (Santiago, Imprenta de Los Tiempos).

Huneeus, Jorge (1880): La Constitución Ante el Congreso, o Sea Comentario Positivo de la Constitución Chilena. Segunda I Última Parte (Santiago, Imprenta de Los Tiempos).

Jaksic, Iván (1989): Academic Rebels in Chile. The Role of Philosophy in Higher Education and Politics (New York, State University of New York Press).

JocelYn-Holt, Alfredo (1998): "El Liberalismo Moderado Chileno. Siglo XIX”, Estudios Públicos, vol. 69: pp. 439-485.

Lastarria, J.V. y Errázuriz, F. (1850): Bases de la Reforma (Santiago, Imprenta del ProgreSO).

Lastarria, José Victorino (1861): Don Diego Portales, Juicio Histórico (Santiago, Imprenta El Correo).

Lastarria, José Victorino (1865): Elementos de Derecho Público Constitucional Teórico, Positivo I Político Y La Constitución Politica de La República de Chile Comentada (Gante, Imprenta de Eug. Vanderhaeghen, 3a ed.).

Lastarria, José Victorino (1865): La América (Buenos Aires, Argentina: Imprenta del Siglo).

Lastarria, José Victorino (1868): La Reforma Politica. Única Salvación de La República. Único Medio de Plantear La Semecracia O El Gobierno de Si Mismo (Santiago, Imprenta de la Libertad).

Lastarria, José Victorino (1874): Lecciones de Politica Positiva (Santiago, Imprenta de El Ferrocarril). 
LASTARria, José Victorino (1878): Recuerdos Literarios (Santiago, Imprenta de la República de Jacinto Núnez).

Lastarria, José Victorino (1896): Elementos de derecho Público Constitucional (Quito, Imprenta Americana).

LeTELIER, Valentín (1917): Génesis del Estado y de Sus Instituciones Fundamentales (Buenos Aires, Cabaut y Cía. Editores).

Muñoz L., Fernando (2005): "Notas Sobre la Historia Constitucional de Chile: Génesis y Evolución Entre 1810 Y 1970", Anuario de Derecho Constitucional Latinoamericano.

Navarro B., Enrique (2010): "Notas Sobre la Evolución Histórica del Control de Constitucionalidad de las Leyes en Chile", Revista Chilena de Historia del Derecho, vol. XXII: pp. 1231-1255.

Navarro B., Enrique (2011): El Control de Constitucionalidad de las Leyes en Chile (18112011) (Santiago, Cuadernos del Tribunal Constitucional, vol. 43).

Nogueira A., Humberto (1993): "La Justicia Constitucional Como Defensa de la Constitución”, Revista Chilena de Derecho, P. Universidad Católica de Chile, vol. XX: pp. $417-$ 439.

NúNÉEZ P., Manuel (2012): “Desaplicación e Inaplicación Jurisdiccional de las Leyes en Chile: Ejercicio de la Jurisdicción y Control Concreto de Constitucionalidad", Revista de Derecho, Universidad Católica del Norte, Año 19-No 2: 191-236.

Oyarzún, Luis (1953): El Pensamiento de Lastarria (Santiago, Editorial Jurídica de Chile, vol. 33).

Peña T., Marisol (2011): Aportes del Tribunal Constitucional de Chile al Estado de Derecho y a la Democracia (Santiago, Cuadernos del Tribunal Constitucional, vol. 47).

Quinzio F., Jorge (1969): Manual de Derecho Constitucional. (Santiago, Editorial Jurídica de Chile).

Raveau, Rafael (1939): Tratado Elemental de Derecho Constitucional Chileno y Comparado. (Santiago, Editorial Nascimento, 2da ed.).

Ribera N., Teodoro (1987): "Función Y Composición del Tribunal Constitucional de 1980", Centro de Estudios Públicos, vol. 27: pp. 77-112.

Ríos Á., Lautaro (2002): "El Control Difuso de Constitucionalidad de las Leyes en la República de Chile", Revista de Derecho, P. Universidad Católica de Valparaíso, vol. XXIII: pp. 39-67.

Roldán, Alcibíades (1917): Elementos de Derecho Constitucional de Chile (Santiago-Valparaíso, Soc. Imprenta-Litográfica Barcelona, 2da ed.).

SACKS, Norman (1972): “José Victorino Lastarria: Un Intelectual Comprometido en la América Latina,” Revista Chilena de Historia y Geografia, vol. 140: pp. 153-193.

SACKS, Norman (1988): "Lastarria y Sarmiento: El Chileno y el Argentino Achilenado", Revista Iberoamericana LIV- 143 (1988): pp. 491-512.

SACKS, Norman (1988-A): "José Victorino Lastarria Y Henry Thomas Buckle: El Positivismo, La Historia Y España”, en Estudios Sobre José Victorino Lastarria (Santiago, Ed. de la Universidad de Chile) pp. 123-151.

Sagredo B., Rafael y Devés V., Eduardo (1991): Discursos de José Manuel Balmaceda. Iconografía (Santiago, DIBAM, Centro de Investigaciones Diego Barros Arana). 
Silva B., Alejandro (1963) Tratado de Derecho Constitucional, Tomo II (Santiago, Editorial Jurídica de Chile).

Silva B., Alejandro (1963-A) Tratado de Derecho Constitucional, Tomo III (Santiago, Editorial Jurídica de Chile).

Silva, Patricio (2008): In the Name of Reason. Technocrats and Politics in Chile (EE.UU., The Pennsylvania State University Press).

Subercaseaux, Bernardo (1981): Cultura y Sociedad en el Siglo XIX: Lastarria, Ideología y Literatura (Santiago, Editorial Aconcagua).

Varas A., Paulino (1984): "El Nuevo Concepto de Ley En La Constitución de 1980", Revista Chilena de Derecho, vol. XI: pp. 377-384.

VAras A., Paulino (2013): "Homenaje a los Profesores José Victorino Lastarria y Jorge Huneeus en los 170 Años de Enseñanza del Derecho Constitucional”, Revista de Derecho Público, Universidad de Chile, vol. 79: pp. 231-236.

Woll, Allen (1976): "Positivism and History in Nineteenth-Century Chile: José Victorino Lastarria and Valentín Letelier", Journal of the History of Ideas, vol. 37: pp. 493-506.

Zapata L., Patricio (2008): Justicia Constitucional. Teoría y Práctica en el Derecho Chileno y Comparado. (Santiago, Editorial Jurídica de Chile).

Zapata L., Patricio (2002): La Jurisprudencia del Tribunal Constitucional. Parte General. (Santiago, Biblioteca Americana, Universidad Andrés Bello).

ZúNiga U., Francisco (2002): Elementos de Jurisdicción Constitucional, Tomo II (Santiago, Universidad Central de Chile).

ZúNiga U., Francisco (2002-A): "Jurisdicción Constitucional en Chile. Un Balance Crítico”, en Vega, J. y Corzo, E. (ed.), Tribunales y Justicia Constitucional (México: Instituto de Investigaciones Jurídicas - Universidad Nacional Autónoma de México) pp. 441-534. 